\title{
COGNITIVE ASSESSMENT IN FIBROMYALGIA PATIENTS OF AN OUTPATIENT CLINIC
}

Ana Carla Fernandes Oliveira, ${ }^{1, \star}$, Fernanda Tavares de Melo Cavalcanti', Maria Roberta Melo Pereira Soares', Isabella Araújo Mota Fernandes ${ }^{1}$, Eutília Andrade Medeiros Freire', Alessandra de Sousa Braz ${ }^{1}$

1.Universidade Federal da Paraíba, João Pessoa (PB), Brazil.

*Corresponding author: anacarlaem@hotmail.com

\section{BACKGROUND}

Clinical features of fibromyalgia (FM), besides chronic and widespread pain, include sleep disturbances, mood disorders and cognitive impairment. Cognition status is an important parameter about FM, once it is part of the 2016 American College of Rheumatologists (ACR) criteria, used for both diagnosis and assessment of disease severity. Poor cognitive performance is a common complaint among patients followed at a chronic pain outpatient clinic, mostly referred as lack of memory and loss of concentration ability. The purpose of this study is to evaluate the cognitive function in this group of patients and observe the occurrence of cognitive impairment using specific tests.

\section{MATERIALS AND METHODS}

A cross-sectional epidemiological study was conducted from August 2019 to January 2020, with 18 to 60-year-old individuals who met the 2016 ACR preliminary criteria, and which signed the informed consent document. Socioeconomic questionnaire and cognitive assessment screening tests (mini mental state examination - MMSE and verbal fluency test - animal category - VFT) were applied. Information about comorbidities and therapy were also collected.

\section{RESULTS}

The sample consisted of 51 patients, $100 \%$ women, mean age 49.94 years (SD \pm 7.31 ), $64.7 \%$ non-white, $35.29 \%$ white. They received drug treatment in $90.19 \%$ of cases. Mini mental state examination averaged 23.63 (SD \pm 3.654 ) and VFT 12.08 (SD \pm 3.862 ). About $37 \%$ of the patients had a good performance in both tests. Mini Mental State Examination performance was worse in patients with 1 to 8 years of schooling and better in individuals with more than 8 years of schooling $(p=0.000)$. Otherwise, when evaluated with TVF, patients shown worse results in those with 8 or less years of schooling and those with over 12 years of study $(p=0.150)$. There were worse results in MMSE patients who are retired or housewives when compared to those who perform some activity outside home $(p=0.035)$.

\section{CONCLUSION}

More than $60 \%$ of the women evaluated had poor result in least one of the cognitive tests. Patients with lower pain indices had better cognitive outcomes when assessed by MMSE, while patients with fewer associated symptoms (represented by the symptom severity score) had better outcomes when undergoing VFT. Worst MMSE performances were observed in patients with fewer years of formal education. Retired women and housewives most often had poor cognitive performance. 